\title{
Pendidikan dan tempat tinggal ibu dengan kejadian perdarahan pada kehamilan di Indonesia
}

\author{
Anjeli Ratih Syamlingga Putri \\ Akademi Kebidanan Indragiri, Jl.H.Syarief, Desa Rantau Mapesai, Seberang, (0769) 21877, Rengat, Kabupaten Indragiri Hulu, \\ Riau, Indonesia
}

\section{INFORMASI ARTIKEL:}

\begin{tabular}{l}
\hline Riwayat Artikel: \\
Tanggal diterima: 12-Agustus-2020 \\
Tanggal direvisi: 12-November-2020 \\
Tanggal dipublikasi: 31-Desember-2020 \\
\hline Kata kunci: \\
Perdarahan pada kehamilan \\
Pendidikan \\
Tempat tinggal
\end{tabular}

\subsection{6/jrki.v4i2.88}

Key word: Antepartum Haemorrhagea Education Residence

\begin{abstract}
ABSTRAK
Latar belakang: Perdarahan antepartum adalah penyebab utama morbiditas dan mortalitas ibu. Ante Partum Haemorhargi (APH) memperumit 0,5-5\% kehamilan yang berhubungan dengan variabel sosiodemografi. Penyebab utama APH adalah plasenta previa dan abruptio placentae. Hasil Survei Demografi Kesehatan Indonesia (SDKI) tahun 2012 menunjukkan 8 persen wanita mengalami pendarahan pada kehamilan. Tujuan penelitian: Mengetahui hubungan Pendidikan dan tempat tinggal dengan kejadian perdarahan antepartum di Indonesia. Metode : Penelitian kuantitatif dengan survay analitik ini menggukanan pendekatan case-control yang menganalisis kejadian perdarahan antepartum berdasarkan data SDKI tahun 2012 dengan jumlah 15.173 responden). Hasil: Analisis data menggunakan chi-squre dengan $p$-value 0,05 dan $\mathrm{Cl} 95 \%$. Hasil bivariat yang didapatkan, pendidikan ibu dikaitkan dengan kejadian perdarahan antepartum dengan $p$-value $(0,008)$. Simpulan: Berdasarkan analisis Health Technology Assesment (HTA), untuk mencegah kejadian peradarahan antepartum pengenalan komplikasi antenatal tepat waktu dan perawatan untuk manajemen komplikasi akan menjadi strategi utama dalam mengurangi kematian ibu dan bayi.
\end{abstract}

\begin{abstract}
Background: Antepartum haemorhagea is the main cause of maternal morbidity and mortality. Ante Partum Haemorhargic (APH) complicates $0.5-5 \%$ of pregnancies associated with sociodemographic variables. The main causes of $A P H$ are placenta previa and placental abruption. The results of the Indonesian Health Demographic Survey (IDHS) in 2012 showed that 8 percent of women experienced bleeding in pregnancy. Objective: The aim of this study was to determine the association of age and history of SC with the incidence of antepartum bleeding in Indonesia. Methods: This quantitative study with analytic surveys uses a case-control approach that analyzes antepartum hemorrhage events based on the 2012 IDHS data with 15,173 respondents. Results: Data analysis using chi-squre with a p-value of 0.05 and $95 \% \mathrm{Cl}$. Bivariate results were obtained, maternal education was associated with antepartum hemorrhage with p-value (0.008). Conclusion: According to a Health Technology Assessment (HTA) analysis, to prevent the occurrence of antepartum outrage on the introduction of timely antenatal complications and treatment for management of complications will be the main strategy in reducing maternal and infant mortality.
\end{abstract}

\section{Pendahuluan}

Pendarahan merupakan penyebab utama morbiditas dan mortalitas ibu hamil dan perinatal yang bahkan merupakan salah satu keadaan darurat yang paling sering terjadi pada kebidanan. Perdarahan dalam kehamilan didefinisikan sebagai perdarahan dari saluran kelamin yang terjadi pada masa kehamilan (Fan et al., 2017).

830 wanita didunia meninggal setiap hari dari penyebab yang dapat dicegah terkait dengan

\footnotetext{
* Korespondensi penulis.

Alamat E-mail: anjeliratih1593@gmail.com
}

kehamilan dan persalinan; 99\% dari 830 kematian setiap hari adalah wanita dari negara-negara berkembang. Di negara maju, perdarahan sebelum melahirkan hanya $16,3 \%$ dari kematian ibu, sementara di Afrika Sub-Sahara yaitu pada $24,5 \%$ (Lankoande et al., 2017)

APH memperumit 0,5-5\% kehamilan yang berhubungan dengan variabel sosiodemografi. Penyebab utama APH adalah plasenta previa dan abruptio placentae; namun penyebab pasti perdarahan dalam beberapa kasus mungkin tidak dapat ditentukan. Komplikasi maternal APH dapat menyebabkan syok hipovolemik, koagulasi 
intravaskular diseminata, dan gagal ginjal akut, operasi caesar yang lebih tinggi, histerektomi peripartum dan anemia pasca operasi. Sedangkan komplikasi janin dapat menyebabkan persalinan prematur, berat badan lahir rendah, asfiksia lahir, dan kematian janin intrauterin (Takai et al., 2017).

Salah satu upaya pemerintah dalam menurunkan angka kematian ibu adalah dengan memberikan pelayanan pra-persalinan yaitu Antenatal Care (ANC) minimal 4 kali. Pelayanan ANC tersebut memiliki peranan yang sangat penting, diantaranya agar dapat dilakukan deteksi dan tata laksanan dini komplikasi yang dapat timbul saat persalinan 7 (KeMenkes, 2013).

Hasil Survei Demografi Kesehatan Indonesia (SDKI) tahun 2012 menunjukkan 46 persen wanita mengalamai komplikasi pada saat melahirkan dan 8 persen diantaranya wanita mengalami pendarahan pada kehamilan (BPS dan Macro International, 2012). Berdasarkan latar belakang tersebut, tujuan penelitian ini adalah untuk mengetahui hubungan paritas dengan kejadian perdarahan antepartum di Indonesia.

\section{Metode penelitian}

Penelitian ini merupakan penelitian kuantitatif pada bentuk desain survey analitik. Desain penelitian yang digunakan adalah case control dengan pendekatan retrospektif. Populasi dalam penelitian ini yaitu seluruh wanita yang berusia 15-49 tahun dengan kelompok kasus ibu yang mengalami kejadian perdarahan antepartum, dan kelompok kontrol yaitu ibu yang tidak mengalami kejadian perdarahan antepartum di Indonesia berdasarkan data SDKI tahun 2012 yang berjumlah 41.782 orang. Yang menjadi kriteria inklusi pada penelitian ini adalah responden yang memiliki data lengkap pada pertanyaanpertanyaan yang berkaitan dengan variabel penelitian dan kriteria ekslusinya adalah responden yang menjawab unknown.

Pada sampel kasus dilakukan teknik pengambilan sampel dengan total sampling yang berarti seluruh wanita yang berusia 15-49 tahun dan mengalami perdarahan antepartum yang setelah di ekslusi berjumlah 542 sampel. Untuk sampel kelompok kontrol adalah seluruh wanita yang berusia 15-49 tahun yang tidak mengalami kejadian perdarahan yang berjumlah 14.661 .
Analisis univariat dilakukan untuk mengetahui distribusi frekuensi karakteristik responden dan distribusi persentase tiap variabel, dan analisis bivariat dilakukan untuk mengetahui interaksi dua variabel dengan uji statistik chisquare dengan $p$-value $<0,05$. Selain itu, untuk mengetahui besar risiko pada penelitian ini dilakukan dengan menghitung odd ratio (OR)

\section{Hasil dan Pembahasan}

Hasil penelitian berdasarkan karaktersitik mencakup usia, Pendidikan, tempat timggal dan paritas disajikan pada Tabel 1.

Tabel 1. Distribusi Frekuensi Variabel dan Karakteristik Responden

\begin{tabular}{|c|c|c|c|c|c|c|c|}
\hline \multirow{3}{*}{ No } & \multirow{3}{*}{$\begin{array}{c}\text { Karakteris } \\
\text { tik }\end{array}$} & \multicolumn{4}{|c|}{ Kelompok } & \multirow{3}{*}{$\underset{\text { (Total) }}{\mathbf{N}}$} & \multirow{3}{*}{$\%$} \\
\hline & & \multicolumn{2}{|c|}{ Kasus } & \multicolumn{2}{|c|}{ Kontrol } & & \\
\hline & & $\mathbf{F}$ & $\%$ & $\mathbf{F}$ & $\%$ & & \\
\hline \multirow[t]{3}{*}{1} & Usia & & & & & & \\
\hline & $\begin{array}{l}\text { Tidak } \\
\text { berisiko }\end{array}$ & 407 & 75,2 & 1059 & 74,9 & 11366 & 74,9 \\
\hline & Bersiko & 134 & 24,8 & 3673 & 25,1 & 3807 & 25,1 \\
\hline \multirow[t]{3}{*}{2} & Pendidikan & & & & & & \\
\hline & Tinggi & 90 & 16,6 & 1867 & 12,8 & 1957 & 12,9 \\
\hline & Rendah & 451 & 83,4 & 12765 & 87,2 & 13216 & 87,1 \\
\hline \multirow[t]{3}{*}{3} & Tempat Tin & & & & & & \\
\hline & Kota & 301 & 55,6 & 6639 & 45,4 & 6940 & 45,7 \\
\hline & Desa & 240 & 44,4 & 7993 & 54,6 & 8233 & 54,3 \\
\hline \multirow[t]{3}{*}{4} & Paritas & & & & & & \\
\hline & Primipara & 189 & 34,9 & 5077 & 34,7 & 5266 & 34,7 \\
\hline & Multipara & 352 & 65,1 & 9555 & 65,3 & 9907 & 65,3 \\
\hline
\end{tabular}

Karakteristik responden dapat dilihat bahwa mayoritas usia ibu tidak berisiko yaitu 11.366 (74,9\%). Sedangkan untuk gambaran pendidikan responden dapat dilihat bahwa responden yang menyelesaikan pendidikan formal SMA dan Perguruan Tinggi hanya 1957 (12,9\%). Karakteristik responden juga dapat dilihat mayoritas responden bertempat tinggal di desa yang berjumlah 8233 (54,3\%). Selain itu, mayoritas responden merupakan multipara yaitu sebanyak 9907 (65,3\%).

Tabel 2 Hubungan Pendidikan dan Tempat Tingga dengan Kejadian Perdarahan antepartum

\begin{tabular}{|c|c|c|c|c|c|c|c|}
\hline \multirow[t]{2}{*}{ Variabel } & \multicolumn{2}{|c|}{ Perdarahan } & \multicolumn{2}{|c|}{ Tidak Perdarahan } & \multirow[t]{2}{*}{ OR } & \multirow{2}{*}{$\begin{array}{c}95 \% \\
\mathrm{Cl}\end{array}$} & \multirow{2}{*}{$\begin{array}{c}\text { P- } \\
\text { value }\end{array}$} \\
\hline & $\begin{array}{c}N=54 \\
2\end{array}$ & $\%$ & $\mathrm{~N}=14661$ & $\%$ & & & \\
\hline Pendidikan & & & & & 1,3 & 1,083 & 0,008 \\
\hline Rendah & 451 & 83,4 & 12765 & 87,2 & 64 & - & \\
\hline Tinggi & 90 & 16,6 & 1867 & 12,8 & & 1,720 & \\
\hline Tempat & & & & & 0,6 & 0,557 & 0,000 \\
\hline Tinggal & & & & & 62 & - & \\
\hline Kota & 301 & 55,6 & 6639 & 45,4 & & 0,787 & \\
\hline Desa & 240 & 44,4 & 7993 & 54,6 & & & \\
\hline
\end{tabular}

Hasil uji statistik antara variabel independent dan variabel dependen menunjukkan terdapat 451 responden $(83,4 \%)$ mempunyai pendidikan rendah 
yang mengalami perdarahan antepartum dan 90 responden $(16,6 \%)$ pendidikan responden yang tinggi dan mengalami perdarahan antepartum dengan $p$-value 0,008 . Hal ini menunjukkan bahwa ada hubungan bermakna antara pendidikan ibu dengan kejadian perdarahan antepartum karena $p$-value $>0,005$ dan rentang $\mathrm{Cl}$ yaitu 1,083-1,720 $(\mathrm{OR}=1,364)$.

Berdasarkan tabel 2 tersebut menunjukkan bahwa terdapat 301 responden $(55,6 \%)$ yang tinggal dikota dan mengalami perdarahan pada kehamilan dan 240 responden $(44,4 \%)$ yang tinggal di desa mengalami kejadian perdarahan pada kehamilan $p$ value sebesar $0,000(\mathrm{OR}=0,662, \mathrm{Cl}=$ $0,557-0,887$. Hal ini menunjukkan ada hubungan yang signifikan antara tempat tinggal dengan kejadian perdarahan antepartum.

\section{Pembahasan}

Perdarahan antepartum adalah penyebab utama morbiditas dan mortalitas ibu serta janin yang menyulitkan 2-5\% dari semua kehamilan. Penyebab utama antepartum adalah plasenta previa berkontribusi $80 \%$, abrupsio plasenta $19 \%$ dan ruptur uterus $1 \%$. Namun, karakteristik ibu seperti pendidikan dan tempat tinggal sering dikaitkan menjadi faktor risiko untuk terjadinya perdarahan antepartum. Oleh karena itu, diharapkan ibu hamil untuk pendaftaran kehamilan secara dini, perawatan ANC teratur dan berkonsultasi, deteksi dini kasus berisiko tinggi, dan rujukan dini ke pusat fasilitas kesehatan yang lebih tinggi, baik fasilitas untuk operasi caesar, ketersediaan bank darah dan pendekatan multidisiplin dengan NICU yang baik, sehingga meningkatkan hasil yang baik bagi ibu dan bayi dari perdarahan antepartum, karena hasilnya akan berakibat fatal tanpa manajemen yang tepat (Njoroge., 2013(Bener et al., 2012) : Tyagi, 2016).

\section{Hubungan Pendidikan Ibu dengan Kejadian Perdarahan antepartum.}

Pada penelitian ini didapatkan bahwa pendidikan ibu memilki hubungan yang bermakna secara statistik dengan kejadian perdarahan antepartum. Hal ini bisa dilihat dari $p$-value yaitu $0,008$ ( $p$-value $<0,05)(\mathrm{OR}=1,364 ; \mathrm{Cl}=1,083-1,720)$. Ibu dengan Pendidikan rendah mempunyai peluang 1,364 kali lebih besar untuk mengalami perdarahan antepartum dibandingkan dengan ibu yang berpendidikan tinggi. Perempuan yang berpendidikan tinggi cenderung lebih memperhatikan kesehatan diri dan keluarganya, sedangkan wanita dengan tingkat pendidikan yang rendah, menyebabkan kurangnya pengertian mereka akan bahaya yang dapat menimpa ibu hamil maupun bayinya terutama dalam hal kegawatdaruratan kehamilan dan persalinan (Pivano et al., 2015).

Hal ini sesuai dengan penelitian A. Bener menjelaskan bahwa prevalensi kejadian perdarahan antepartum pada wanita arab dinegara qatar yang tertinggi pada pendidikan yang lebih rendah dibandingkan dengan wanita yang berpendidikan di universitas (Bener et al., 2012). Hasil penelitian ini tidak sejalan dengan penelitian Mahmudah et al (2013), yang menyatakan bahwa terdapat hubungan antara pendidikan ibu dengan angka kematian perinatal. Bila dibandingkan dengan ibu yang berpendidikan tinggi, ibu dengan pendidikan rendah mempunyai risiko 2,843 kali lebih besar untuk mengalami kematian perinatal.

Pendidikan secara tidak langsung berpengaruh dalam menentukan dan mengambil sebuah keputusan. Tingginya tingkat pendidikan seorang wanita diharapkan semakin meningkat juga pengetahuan dalam mengantisipasi kesulitan kehamilan dan persalinan sehingga termotivasi untuk melakukan pengawasan kehamilan secara teratur (Rahmi, 2009).

\section{Hubungan Tempat Tinggal lbu dengan Kejadian Perdarahan Pada Kehamilan}

Pada penelitian ini, didapatkan bahwa tempat tinggal ibu berhubungan dengan kejadian perdarahan antepartum yaitu $p$-value $=0,000(\mathrm{OR}=$ $0,662, \mathrm{Cl}=0,557-0,887)$. Faktor tempat tinggal bukan menjadi faktor protektif terjadinya perdarahan antepartum.

Faktor demografi dapat menyebabkan perbedaan prevalensi kejadian perdarahan antepartum pada ibu hamil dan bervariasi di berbagai negara (Fan et al., 2017). Pada penelitian Khanam (2016) menunjukkan bahwa tinggal dekat dengan fasilitas kesehatan $(<10 \mathrm{~km})$ secara positif dikaitkan dengan mencari perawatan terlatih untuk komplikasi antepartum dan intrapartum. Hal ini berarti terdapat hubungan yang signifikan antara jarak yang lebih pendek ke fasilitas kesehatan dan mengakses bantuan terampil untuk perawatan intrapartum. Kurangnya akses terhadap transportasi seperti berada di pedesaan tetap 
merupakan tantangan yang terus-menerus di banyak negara berkembang (Khanam, 2016).

Hal ini sesuai dengan teori yang menyatakan bahwa keterjangkauan lokasi tempat pelayanan kesehatan, tempat pelayanan yang lokasinya sulit dicapai oleh para ibu menyebabkan berkurangnya akses ibu hamil terhadap pelayanan kesehatan, jenis dan kualitas pelayanan yang tersedia dan keterjangkauan terhadap informasi dapat mempengaruhi terjadinya komplikasi kehamilan dan persalinan. Akses terhadap tempat pelayanan kesehatan dapat dilihat dari beberapa faktor, seperti lokasi dimana ibu dapat memperoleh pelayanan kontrasepsi, pemeriksaan antenatal, pelayanan kesehatan primer atau pelayanan kesehatan rujukan yang tersedia di masyarakat (WHO, 2008).

\section{Simpulan}

Hasil penelitian menunjukkan ada hubungan pendidkan dan tempat tinggal dengan perdarahan antepartum.

Pemerintah dapat membuat kebijakan untuk membentuk promosi pendidikan wanita hingga tingkat sekolah perguruan tinggi, peningkatan infrastruktur kesehatan dan ketersediaan layanan perawatan obstetrik darurat bagi mereka yang membutuhkan dengan meningkatkan dan melengkapi pusat kesehatan di daerah pedesaan dan perkotaan, menyediakan unit mobil untuk perawatan prenatal untuk menjangkau daerah pedesaan yang tidak tercakup dengan baik oleh fasilitas yang ada, dan menyediakan rumah tunggu bersalin bagi para ibu dari daerah yang tidak dapat diakses dengan masalah transportasi.

\section{Daftar Pustaka}

Badan Pusat Statistik (BPS) dan Macro International. 2012. Survei Demografi dan Kesehatan Indonesia Tahun 2012. Badan Pusat Statistik dan Macro International, Calverton, Maryland, USA.

Bener, A., Saleh, N.M., Yousafzai, M.T., 2012. Prevalence and associated risk factors of antepartum hemorrhage among Arab women in an economically fast growing society. Nigerian Journal of Clinical Practice 15, 185. https://doi.org/10.4103/1119-3077.97315
Fan, D., Wu, S., Liu, L., Xia, Q., Wang, W., Guo, X., Liu, Z., 2017. Prevalence of antepartum hemorrhage in women with placenta previa: a systematic review and meta-analysis. Sci Rep 7. https://doi.org/10.1038/srep40320

Kementrian Kesehatan RI. 2013. Profil Kesehatan Indonesia Tahun 2012. Jakarta

Khanam, R., Creanga, A.A., Koffi, A.K., Mitra, D.K., Mahmud, A., Begum, N., Moin, S.M.I., Ram, M., Quaiyum, M.A., Ahmed, S., Saha, S.K., Baqui, A.H., 2016. Patterns and Determinants of Care-Seeking for Antepartum and Intrapartum Complications in Rural Bangladesh: Results from a Cohort Study. PLoS ONE 11. https://doi.org/10.1371/ journal.pone.0167814

Lankoande, M., Bonkoungou, P., Ouandaogo, S., Dayamba, M., Ouedraogo, A., Veyckmans, F., Ouédraogo, N., 2017. Incidence and outcome of severe ante-partum hemorrhage at the Teaching Hospital Yalgado Ouédraogo in Burkina Faso. BMC Emerg. Med. 17. https://doi.org/10.1186/s12873-017-0128-3

Mahmudah U, Cahyati WH, Wahyuningsih AS. Faktor Ibu dan Bayi yang Berhubungan dengan Kejadian Kematian Perinatal. Jurnal Kesehatan Masyarakat 2011:41-

Njoroge P.L.N., 2013. Risk Factors Of Antepartum Haemorrhage At Kenyyatta National Hospital : A Case Control Study. Nairoby University: Department of Obstetrics And Gynaecology

Pivano, A., Alessandrini, M., Desbriere, R., Agostini, A., Opinel, P., d'Ercole, C., Haumonte, J.-B., 2015. A score to predict the risk of emergency caesarean delivery in women with antepartum bleeding and placenta praevia. Eur. J. Obstet. Gynecol. Reprod. Biol. 195, 173-176. https://doi.org/10.1016/j.ejogrb. 2015.10.015 
Rahmi. "Karakteristik Penderita Perdarahan Post Partum Yang Datang Ke Rumah Sakit Pirngadi Medan tahun 2004- 2008"'[Skripsi]. [Medan]: Fakultas Kesehatan Masyarakat, Universitas Sumatera Utara; 2009
Tyagi Priyanka, Nidhi Y, Parul S, Uma., 2016. Study of antepartum haemorrhage and its maternal and perinatal outcome. International Journal of Reproduction, Contraception, Obstetrics and Gynecolo 